\title{
Numerical Fire Modelling of a Turbine Hall
}

\author{
RISTO HUHTANEN
}

Technical Research Centre of Finland

Nuclear Engineering Laboratory

P.O. Box 169

SF-00181 Helsinki, Finland

\section{ABSTRACT}

Simulation of a fire in a turbine hall has been performed with the PHOENICS-code. The main goal was to state a reasonable collection of models for general fire analysis and to get experience in this kind of simulation. The three-dimensional flow simulation model includes a $k-\varepsilon$ turbulence model, Magnussen's and Hjertager's burning rate model, heat radiation and an economical method to calculate heat conduction in structures. An oil pool has been assumed to burn on the symmetry axis of the hall. The results seem to suit quite well with the qualitative observations from a fire appeared in a turbine hall in Helsinki in 1986.

\section{INTRODUCTION}

Numerical modeliing of a fire in a two unit turbine hall has been performed with the PHOENICS-code. An oil pool fire was supposed to be on the floor. Plume rising from the flame has free advance up to the ceiling. A row of vents is supposed to be open as well as two orifices representing the inflow of the ventilation system (fig 1 ).

The aims of the work have been to state a reasonable collection of models and subroutines for general fire analysis, to get experience in combustion models in large internal fires and to get knowledge of computer resource requirements in this kind of calculation. Also problem definition and the ease of use of the program were of interest. Several fire simulations have been presented in references [1], [2], [3], [4], [5], [7], but they are usually performed in a smaller or different geometry. No publiced experimental results have been available for comparison excluding the quantitative validation study.

The recent three dimensional model includes computation of time dependent flow field, temperature field, turbulence kinetic energy and its dissipation rate, concentration of chemical species and radiation intensities in three coordinate directions. Heat transfer to the structures has been taken into account by a simple and economic manner.

The transience has been simulated with a coarse grid. for 12 minutes and with a finer grid for six minutes. 


\section{COMPUTATION METHOD}

Analysis has been done with the computer code PHOENICS of CHAM Ltd.

The time averaged conservation equations for mass, three velocity components, enthalpy, the mass fractions of fuel, oxygen and burning products, turbulence variables and radiation fluxes are of the general form

$$
\frac{\partial}{\partial t}(\rho \Phi)+\nabla \cdot(\rho \vee \Phi-\Gamma \nabla \Phi)=S_{\Phi}
$$

where $\rho, \vec{v}, \Gamma_{\phi}$ and $S_{\phi}$ are density, velocity vector, effective exchange coefficient of $\Phi$ and a source term for variable $\Phi$. The form of the source term is specific for the variable in question and it can be modified according to the problem. The detailed description of the method is presented for instance in articles [1], [4].

For heat radiation a six-flux model is used. The radiation equations include only the diffusion and source terms. The model is described in reference [5].

\section{PHYSICAL MODELS}

The atmosphere in the building has been considered as a gas mixture composed of oxygen, vaporized fuel and burning products. Nitrogen is present as a passive component. All components are treated as ideal gas. Temperature is calculated from enthalpy which includes the chemical enthalpy of the fuel.

Combustion of fuel has been approximated as a one step reaction in which the results are carbon dioxide and water vapour. For burning rate Magnussen's and Hjertager's eddy break up model is used [1]. It controls the burning rate by turbulent mixing of the vaporized fuel and oxygen

$$
R_{f u}=-A \rho \frac{\varepsilon}{k} \underset{k i n[m}{\operatorname{fu}} \underset{s}{-\infty}
$$

where $A$ is a parameter usually having the value $4 ., \varepsilon$ the dissipation of turbulence kinetic energy, $k$ the turbulence kinetic energy, $m_{o x}$ the mass fraction of oxygen, and $s$ the stoichiometric amount of oxygen required to burn $1 \mathrm{~kg}$ of fuel.

Turbulence has been described with the $k-\varepsilon$ model [6]. The basic assumption in the model is that turbulence is isotropic. However, in a flow where buoyancy effects are strong, turbulence is highly anisotropic. The effect of buoyancy has been taken into account by adding a source term to the $k$ and $\varepsilon$ equations [6].

In radiation heat transfer the absorption coefficient depends on the fraction of different components. As well known, two atomic gases like nitrogen and oxygen are almost transparent and so absorption is influenced only by carbon dioxide, water vapour and soot particles. In this stage, however, a constant absorption coefficient throughout the 
space has been used.

\section{GEOMETRY AND DISCRETIZATION}

The simulated half of a two unit turbine hall has a length of $40 \mathrm{~m}$, a width of $55.5 \mathrm{~m}$ and a height of $29.6 \mathrm{~m}$, in the $\mathrm{x}-, \mathrm{y}-$ and $z$-directions in figure 1. The volume is blocked partly by platforms, turbines, tube arrays, different size of tanks and heat exchangers and by the control room of the power plant. All obstacles are not shown in the figure. The net volume is about $55000 \mathrm{~m}^{3}$. There are two ventilation inlets to the hall. The first is on the floor level and the other $15 \mathrm{~m}$ above the floor having cross sections of $18 \mathrm{~m}^{2}$ and $9 \mathrm{~m}^{2}$ respectively. Hot air flows out through vents near the ceiling. The outlet cross section is $40 \mathrm{~m}^{2}$.

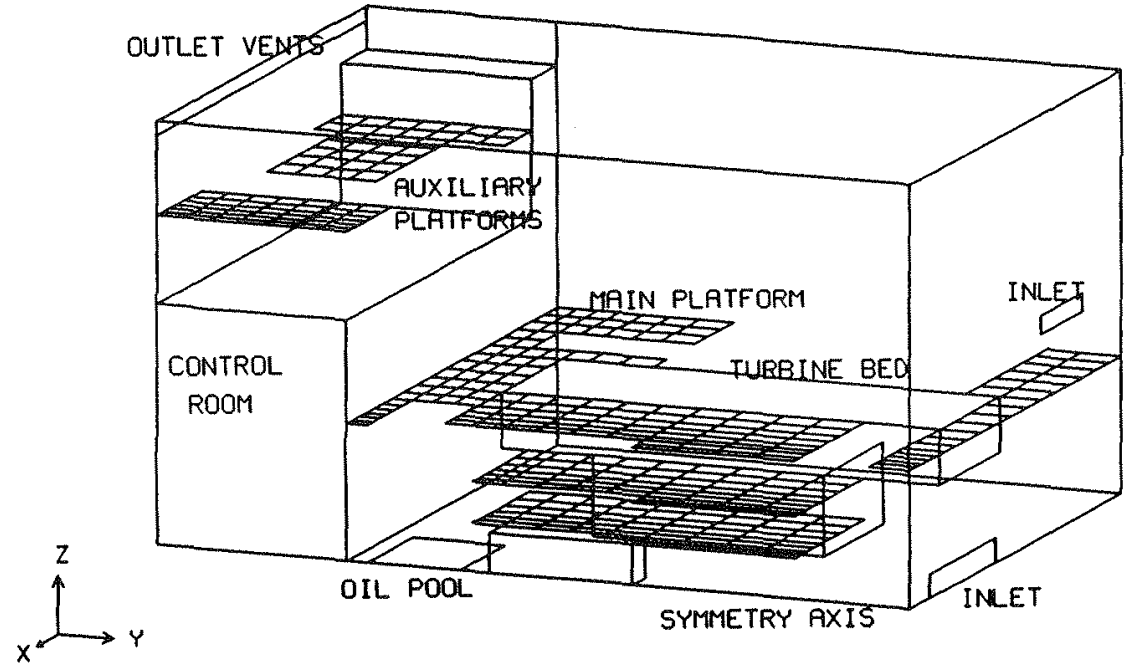

Figure 1. Geometry of the modelled volume. The totally blocked cells as well as platforms are shown.

The origin of the fire, the oil pool, is on the floor next to the control room wall. It is located so that the plume rising up has free advance to the ceiling through the openings on the main platform.

Two different grids of $9 * 12 * 12$ and $18 * 24 * 24$ cells has been used. The geometry description in the program has been done by blocking some of the cells partly or totally.

\section{BOUNDARY CONDITIONS}

The area of the oil pool is $100 \mathrm{~m}^{2}$. The vaporizing rate of $3 \mathrm{~mm} / \mathrm{min}$ in the pool supplies a fuel flow of $4.25 \mathrm{~kg} / \mathrm{s}$. If the fuel is burnt totally with the same rate, the power outlet is about $180 \mathrm{MW}$. 
At the beginning of the simulation the air in the hall is at rest. At inlet and outlet boundaries the standard atmospheric pressure is applied. Inflow is defined according to Bernoulli's equation. Outlet massflow is defined by setting the pressure to the same value that prevails in the atmosphere at the same level.

Initial values for temperature are taken equal for gas and the structures. The temperature of the walls is calculated separately wall by wall. Heat conduction in the structures is calculated onedimensionally in a separate subroutine. Up to eleven structures has been used: roof above the plume, the rest of the roof, control room wall near the flame, other concrete walls and steel element walls. The subroutine utilizes the sum of convective and radiative heat fluxes. As far, a constant heat transfer coefficient has been used for convection.

\section{RESULTS}

For economical reasons the work was started with a coarse grid. In this stage the heat transfer to the structures and the radiation model were omitted. Fuel flow was constant from the beginning of the simulation. This lead to very rapid increase in burning rate. Alr and burning products came out from every orifice. In the beginnig when stratification was not present and inflow jets were not very strong there formed an internal loop. In the plume gas went up and the cold air by the ceiling came down on the other side of the hall. When the plume had spread under the whole ceiling the flow was changed essentially to two layer flow. Hot gas took the upper part of the hall and cold air the lower part. Mixing inside the two layers was good but they were separated by a temperature gradient. The flow turned to throughflow at about 40 seconds after ignition. The flow field reached nearly a steady state condition in 5,.7 minutes. After 9 minutes the temperature was so high that the windows near the ceiling on the wall opposite to the outlet were supposed to be broken. is new (nearly) steady condition with higher massflow and lower temperatur values were reached in about 12 minutes after ignition. The local temperature values were lower than expected. In the flame area even $300 \ldots 400 \mathrm{~K}$ degrees lower than the free flame temperatures. This is caused by the numerical diffusion in a coarse grid.

In the finer grid case the fuel inflow was increased linearly from zero to the nominal value in 120 seconds. Thus the gas expansion was not so abrupt as in the previous case. The flow turned to throughflow within 15 seconds. The overall flow pattern was the same, but temperature and velocity gradients were steeper. The simulated time was 6 minutes which is enough for the flow field to reach a fully developed stage. Figure 2 presents the profile of the vertical velocity on two levels. The maximum plume velocity was $14 \mathrm{~m} / \mathrm{s}$. Maximum velocity downwards in the whole area was $1.9 \mathrm{~m} / \mathrm{s}$. In figure 3 some streamlines and velocity vectors are presented. In the figure there can be seen separate loops in upper and lower part of the hall. The maximum velocity under the ceiling was 6.8 $\mathrm{m} / \mathrm{s}$ and typical values were $2 \ldots 5 \mathrm{~m} / \mathrm{s}$. The velocities in the volume were in general under $2 \mathrm{~m} / \mathrm{s}$ except in the plume, under the ceiling and in inflow jets. The inflow velocities were $9.8 \ldots 11 \mathrm{~m} / \mathrm{s}$. As can be seen it is difficult to get a vision of the velocity field of a three dimensional flow field with only few pictures. 


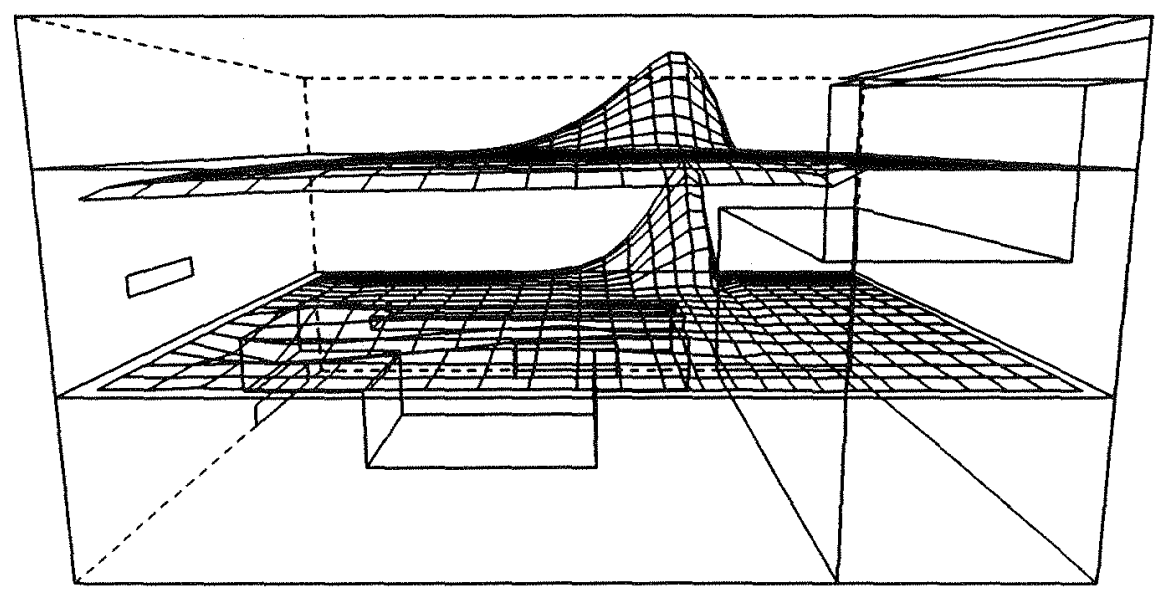

Figure 2. Vertical velocity profile on levels $z / H=0.35$ and $z / H=0.75$. The values are between $-1.5 \ldots 13 \mathrm{~m} / \mathrm{s}$ and $-1.9 \ldots 11 \mathrm{~m} / \mathrm{s}$ respectively. The time is 360 seconds after ignition.

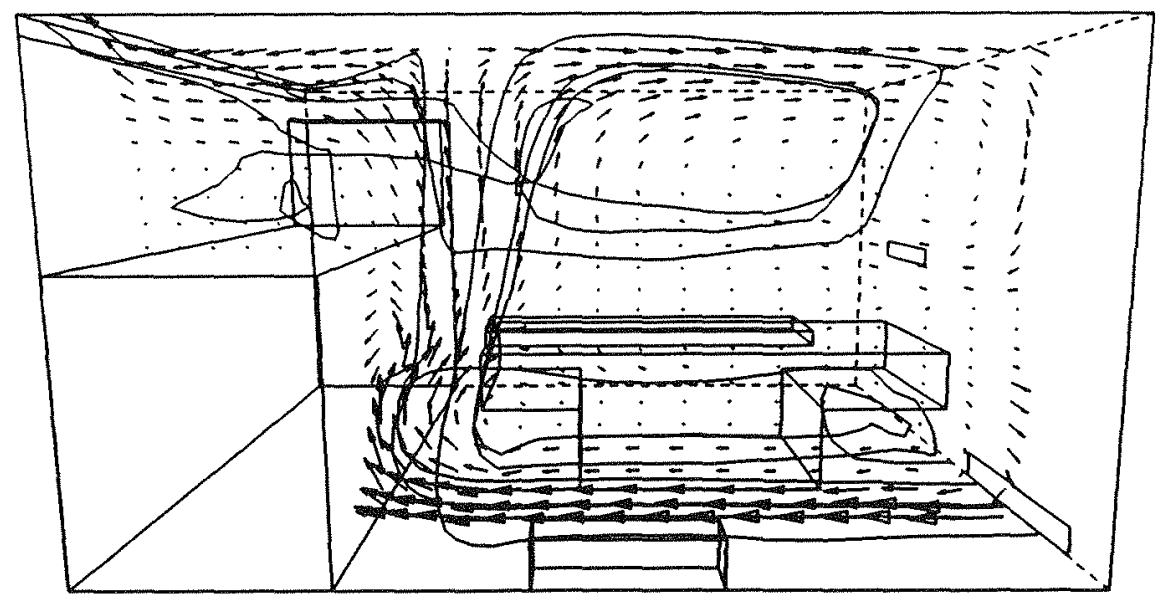

Figure 3. Velocity vectors at plane $x / X=0.8$ at time 360 seconds after ignition. Maximum velocity $10 \mathrm{~m} / \mathrm{s}$. Streamlines starting from the lover. inlet. Note that the streamlines are not in the same plane as the velocity vectors. 
The temperature values were considerably influenced by the grid refinement. Without heat transfer to structures and radiation losses the highest values were $2200 \mathrm{~K}$. Hith those sources applied the maximum temperature was $1500 \mathrm{~K}$. The plume temperature decreased by entrained air with height beeing less than $1000 \mathrm{~K}$ at $8 \mathrm{~m}$ from the pool. In figure 4 the temperature surfaces of $373 \mathrm{~K}$ and $473 \mathrm{~K}$ are presented. Figure 5 presents temperature profiles in two planes. The gradient between the upper and lower area is not very steep but it can be clearly seen.

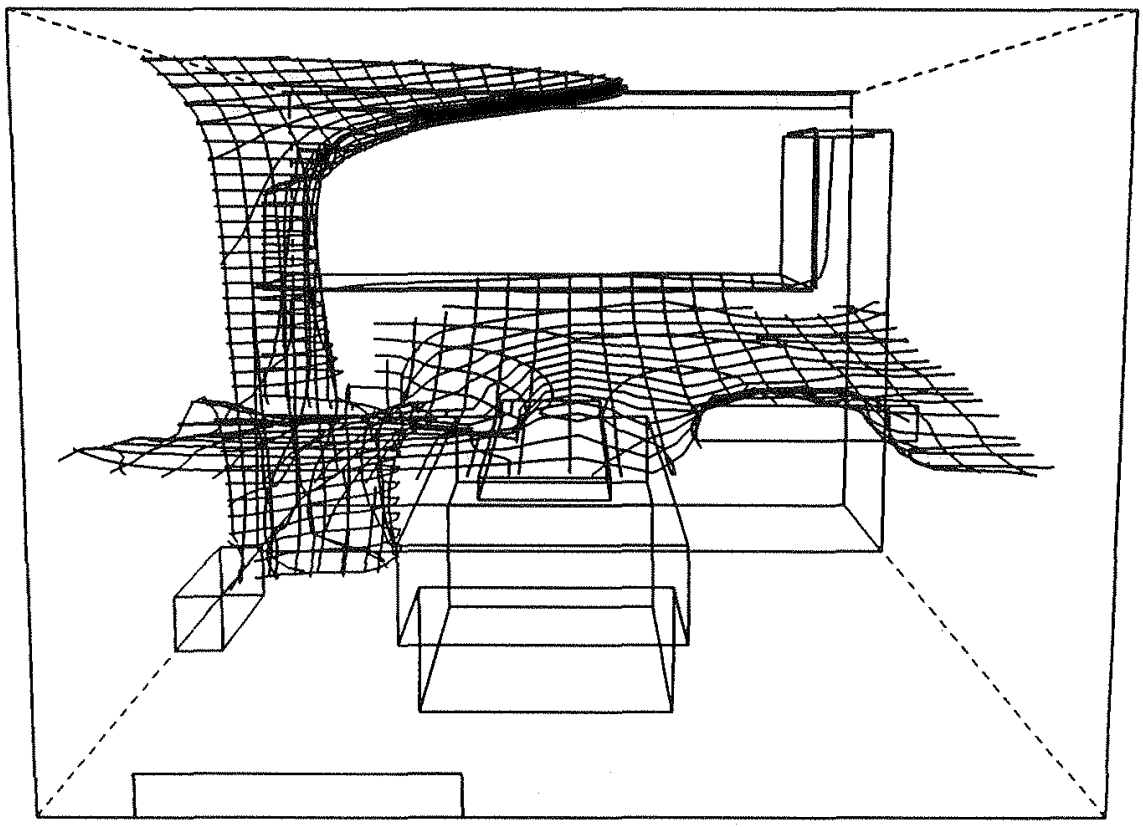

Figure 4. Temperature surfaces of $373 \mathrm{~K}$ and $473 \mathrm{~K}$.

Heat transfer to the structures can be defined from the energy balance. Table 1 presents massflow and heat transfer as a function of time. In table 2 there are surface temperatures of some structures and the temperature range of gas in contact with the structure.

Table 1. Massflow and heat transfer during the transient stage.

$\begin{array}{rrccr}\begin{array}{r}\text { time } \\ \text { [s] }\end{array} & \begin{array}{r}\text { outflow } \\ {[\mathrm{kg} / \mathrm{s}]}\end{array} & \begin{array}{c}\text { outflow } \\ \text { temp [K] }\end{array} & \begin{array}{l}\text { heat transfer to heat trans } \\ \text { structures [MW] }\end{array} \\ 60 & 200 . & 335 \ldots 415 & 7.6 & 37.8 \\ 120 & 318 . & 395 \ldots 500 & 17.8 & 66.9 \\ 180 & 330 . & 405 \ldots 490 & 24.8 & 67.9 \\ 240 & 344 . & 425 \ldots 490 & 20.8 & 69.5 \\ 300 & 350 . & 435 \ldots 500 & 19.2 & 71.6 \\ 360 & 352 . & 440 \ldots 520 & 17.7 & 73.2\end{array}$


Mass fraction of the burning products is presented in figure 6 . The fraction under the main platform is higher than expected. This might be due to numerical diffusion, which is rather effective also in the finer grid.

Table 2. The surface temperature of some typical structures and the contacting gas temperature range at 6 minutes after ignition.

Structure

ceiling above the plume

the rest of the ceiling

steel element wall

concrete wall near the flame

concrete wall far from the flame

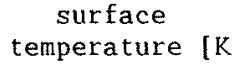

440

376

420

380

299 gas temperature $[\mathrm{K}]$

$495 \ldots 580$

$430 \ldots 530$

$350 \ldots 440$

$465 . .1350$

$300 \ldots 340$

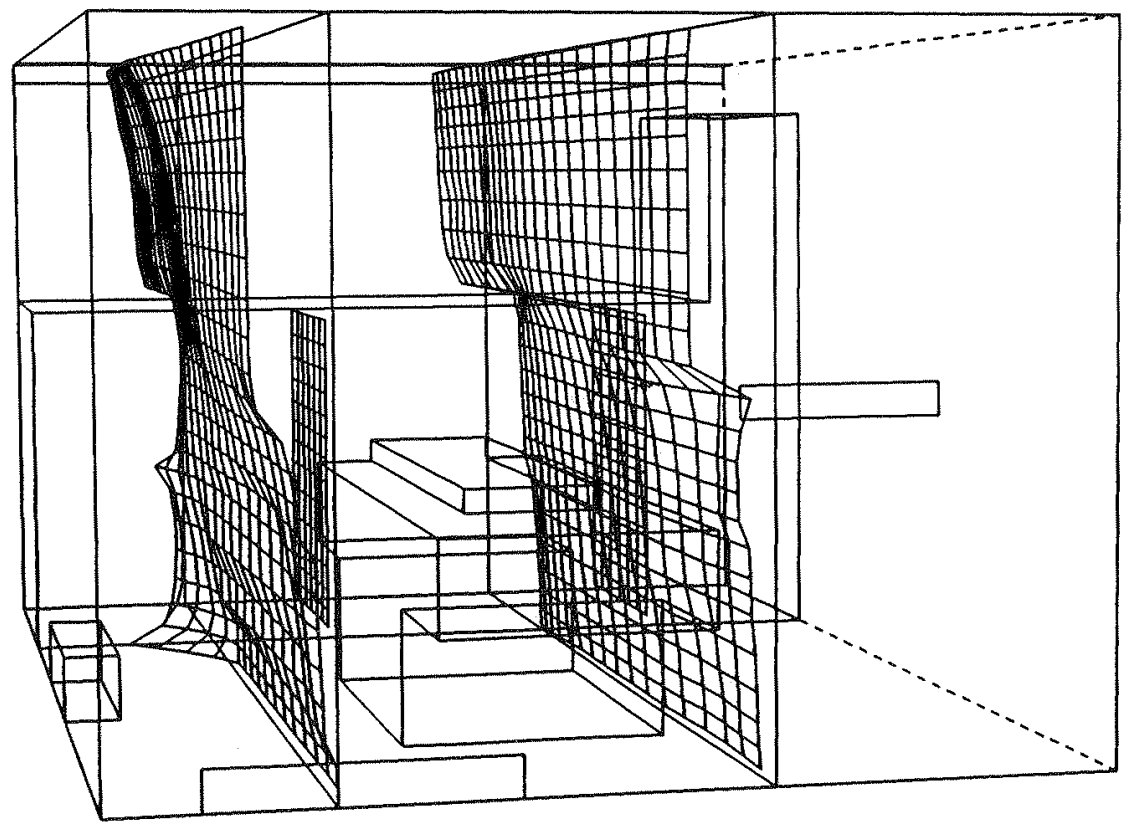

Figure 5. Temperature profiles at locations $x / X=0.35$ and $x / X=0.78$. Temperature ranges are $300 \ldots 470 \mathrm{~K}$ and $290 \ldots 520 \mathrm{~K}$ respectively.

\section{CONCLUSIONS}

Simulation of a fire in a two unit turbine hall was performed with the computer code PHOENICS utilizing the $k-\varepsilon$ model, turbulence dependent 


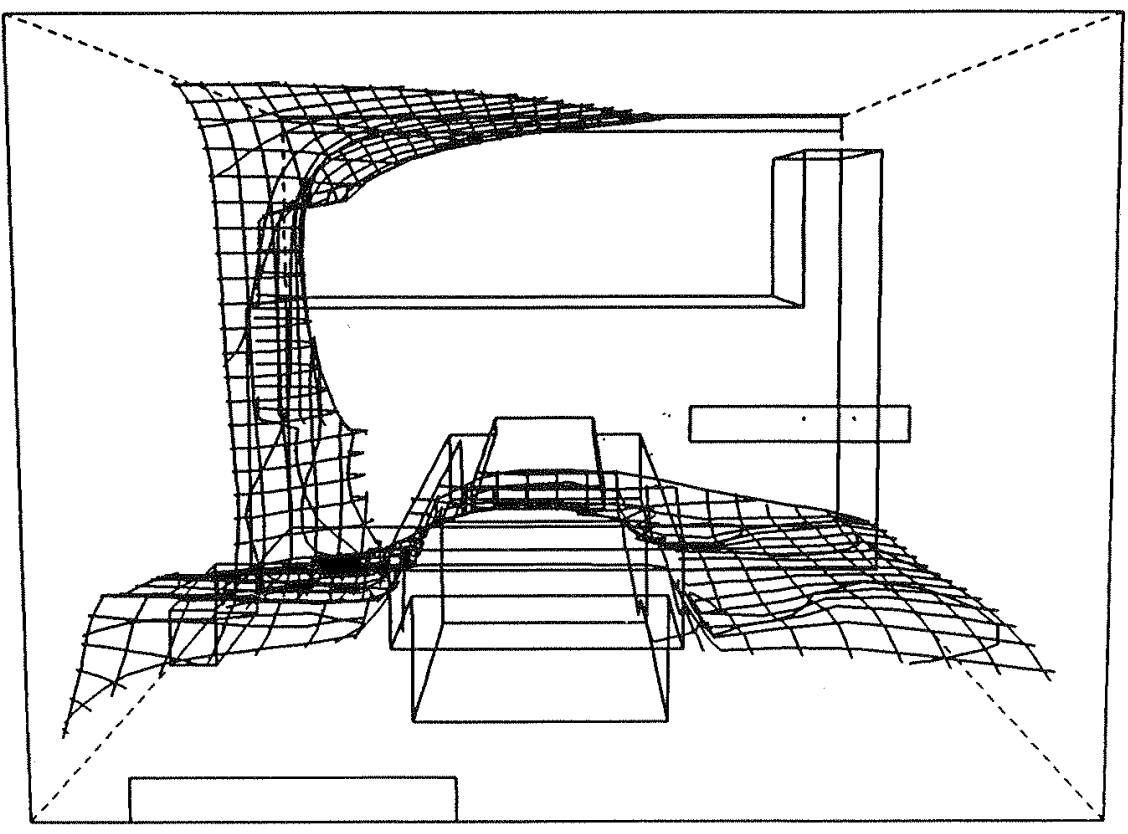

Figure 6. Surfaces of mass fraction of burning products. The upper surface value is $2.5 \%$ and the lower $0.5 \%$.

burning rate model, heat radiation and heat transfer to the structures. Those physical quatities, which are considered be known at least in some reliability, as temperatures and velocities, seem to have the proper values. The simulated case is very much similar to the fire occured in a turbine hall of Hanasaari power plant in Helsinki in June 1986. In both cases cool air flowed in to the floor level under the main platform under which the temperature values were relatively low.

Definition of the problem geometry and boundary conditions is not very difficult. The more complex thing is how to choose the proper physical models so that the essential features of the case are modelled.

Computer time used in the coarse grid was 29.3 CPU hours in a 540 second transient. In finer grid the CPU time has been 225 hours for a six minute transient with radiation model and the structures. The computer used is a microvaX II with a $16 \mathrm{MB}$ central memory. Simulation of a flow field in a fire seems to need a plenty of computer time. In the finer grid there is about 8000 active cells. Each cell has 13 variables involved, which altogether makes 104000 unknowns to be solved on every time step.

In general the code seems to be quite usefull for this kind of fire simulation especially because there is no or very little measured data for such a large events as a turbine hall fire. 


\section{REFERENCES}

1. G. Cox, S. Kumar: Field modelling of fire in forced ventilated enclosures. Combustion Science and Technology, 1987, vol 52, pp. $7-23$.

2. G. Cox, S. Kumar, N.C. Markatos: Some field model validation studies. Fire safety science. Proceedings of the first international symposium. Hemisphere 1986.

3. E.R. Galea, N.C. Markatos: A review of mathematical modelling of aircraft cabin fires. Applied mathematical modelling, 1987, vol 11, June, pp.162-176.

4. N.C. Markatos, M.R. Malin, G. Cox: Mathematical modelling of buoyancy-induced smoke flow in enclosures. 'International Journal of Heat and Mass Transfer, vol 25, p.63-75, 1982 .

5. N.C. Markatos, K.A. Pericleous: An investigation of three dimensional fires in enclosures. ASME/AICHE, HTD, Vol 25, 1983. Proceedings of 21 st National Heat Transfer Conference.

6. S. Kumar: Mathematical modelling of natural convection in fire A state of the art review of the field modelling of variable density turbulent flow. Fire and materials, Vol 7, No 1, 1983, pp.1-24.

7. S. Kumar, G. Cox: Mathematical modelling of fires in road tunnels. 5 th International Symposium on the Aerodynamics \& Ventilation of Vehicle Tunnels. Lille, France, 20-22 May, 1985. 


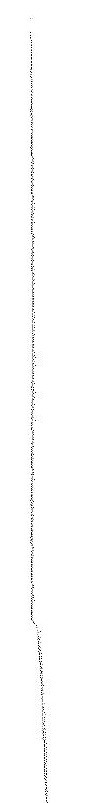

